\title{
Interventional Radiology in Côte d'Ivoire: Analysis and Assessment of the Radiological Risk of the Surgical Team
}

\author{
Kouakou Omer ${ }^{*}$, Koudou Djakouri,2, Djoman Djama Alfred Agbo1, \\ Gogon B. D. L. Huberson 1,3, Monnehan Georges Alain 1,3, Aka Antonin Koua1,3
}

\footnotetext{
${ }^{1}$ Laboratoire de physique nucléaire et radioprotection, Unité de Formation et Recherche, Sciences des Structures de la Matière et Technologie, université Félix Houphouët Boigny, 22 BP 582 Abidjan, Côte d'Ivoire

${ }^{2}$ Higher Normal School, Abidjan, Côte d'Ivoire

${ }^{3}$ Autorité de régulation de sureté et de sécurité nucléaires, 08 BP 4028 Abidjan 08, Abidjan Cocody—Riviera Bonoumin Rond-Point Alassane Ouattara, Abidjan, Côte d'Ivoire

Email: *ladjuepe@gmail.com
}

How to cite this paper: Omer, K., Djakouri, K., Agbo, D.D.A., Huberson, G.B.D.L., Alain, M.G. and Koua, A.A. (2021) Interventional Radiology in Côte d'Ivoire: Analysis and Assessment of the Radiological Risk of the Surgical Team Open Journal of Applied Sciences, 11, 216-229.

https://doi.org/10.4236/ojapps.2021.112015

Received: December 9, 2020

Accepted: February 23, 2021

Published: February 26, 2021

Copyright $\odot 2021$ by author(s) and Scientific Research Publishing Inc. This work is licensed under the Creative Commons Attribution International License (CC BY 4.0).

http://creativecommons.org/licenses/by/4.0/

\begin{abstract}
Ionizing radiation is widely used in medical practice for both diagnostic and therapeutic purposes. However, they are not devoid of adverse health effects on exposed operators. Therefore, we propose to assess the radiological risk of the interventional radiology team of the International Polyclinic of Indénié of Abidjan during the procedures of Embolization of uterine fibromyomas. The effective and equivalent doses to the extremities and crystals were estimated by TLD dosimeters positioned at different body areas selected on the basis of a radiological analysis of the exposure of personnel during five procedures. The analysis of fluoroscopic and record times showed variability in or an average fluoroscopy time of $32.37 \mathrm{~min}$ with extremes of 25.14 to $56.32 \mathrm{~min}$; average record time of $0.52 \mathrm{~min}$ with extremes of $0.12 \mathrm{~min}$ to $1 \mathrm{~min}$. The annual effective doses were respectively, $4.04 \mathrm{mSv}, 3.42 \mathrm{mSv}, 2.84 \mathrm{mSv} ; 2.28 \mathrm{mSv}$, in the Radiologist (R), Operator Assistant (O2); Anesthesiologist (A2), Manipulator (M2). The annual equivalent doses to the radiologist's predominant extremities and lenses were left index and left lens with values of $37.07 \mathrm{mSv}$ and $9.46 \mathrm{mSv}$. The estimated doses in our study are reassuring from a regulatory point of view of dose limits. The results of our work have shown no significant short-term danger to the health of personnel.
\end{abstract}

\section{Keywords}

Interventional Radiology, Embolization of Uterine Fibromyomas, Radiological Risk, Radiation Protection 


\section{Introduction}

Interventional imaging is the field of activity bringing together diagnostic and therapeutic procedures performed under radiological control through the use of $\mathrm{X}$-rays by fluoroscopy (or fluoroscopy) technique to visualize irradiated structures in "real time". In recent years, radio-guided acts, in particular in interventional radiology, have developed considerably. The complexity of these procedures and the duration of X-ray use can lead to significant exposures in patients and operating teams. The health risks induced in the event of patient overexposure are essentially deterministic effects, of the radiological burn type (erythema, dry or exudative epidermis, radionecrosis) and an increased risk of the occurrence of stochastic effects, and therefore of radiation-induced cancers. For exposed workers, the deterministic effects observed are most often chronic radiodermatitis or radiation-induced lens opacities, in addition to an increased risk of radiation-induced cancer [1]. In Ivory Coast, the International Polyclinic of Indénié (PII) is one of the recent centers where interventional medical activities are routinely practiced. As soon as it was commissioned in 2018, the Radiation Protection and Nuclear Safety Authority (ARSN) carried out a technical visit of the room followed by regular control inspections. The contacts identified submitted to the nuclear physics and radiation protection team at Félix Houphouët Boigny University, such as non-conformities in radiation protection, the lack of quality control of the installation and the malfunction in the technical design of the room were subjected to radiological analysis. Given the lack of studies and dose analysis in the interventional radiology specialty, the very first dosimetric study using the thermoluminescent technique was carried out with the aim of minimizing the stochastic effects and avoiding the deterministic effects linked to the use of ionizing $\mathrm{X}$ radiation. This work, carried out under the usual working conditions of operators, aims to establish a dosimetric database by estimating the effective and equivalent doses received to the extremities and to the lens of the interventional radiology intervention team during the procedures of Uterine Fibromyoma Embolization.

\section{Materials and Methods}

\subsection{Radiological Risk Analysis}

\subsubsection{Description and Irradiation Condition of the X-Ray Device}

The medical device identified as the source of personnel exposure shown in Figure 1 is the "Innova version 330" imaging system. It is a fixed installation, the main component of which is the block arch fitted with the tube. X-ray on one side and GE's exclusive revolutionary advanced digital detector, solid-state on the other side. It is these two elements that are involved in worker exposure. In practice, the arrangement of the device conditions the direction of the primary $\mathrm{X}$-ray beam, which in our study is vertical and ascending, the X-ray tube is located under the table. In our case the high frequency and voltage ranges of the $\mathrm{X}$-ray tube are located respectively between $20 \mathrm{kHz}-60 \mathrm{kHz}$ and $40 \mathrm{kV}-125$ 


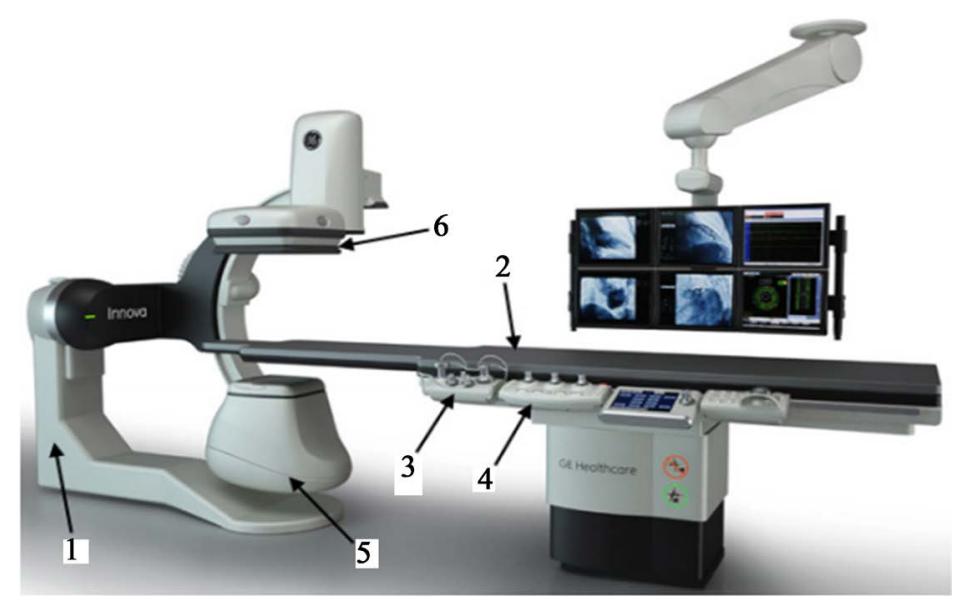

Figure 1. The Innova cardiovascular imaging system.

$\mathrm{KV}$. The maximum current is $1000 \mathrm{~mA}$ [2]. In general, the C-arm is configured for posterior-anterior views. Fluoroscopy constants $(\mathrm{kV}$ and $\mathrm{mA})$ are automatically adjusted.

\subsubsection{Risky Procedures}

The activity of the site is essentially a diagnostic and therapeutic activity. Thus, we collected general administrative data during the period from 2018 to 2020 . The analysis of these data made it possible to know in the interventional radiology specialty that only the embolization of uterine fibromyomas is carried out with a frequency of three to five times per month. In our study, five procedures were retained on the basis of the most important month in terms of the number of procedures. For each procedure and patient the practical exposure parameters such as fluoro and record times were observed, edited in a dose report during the period of our study and analyzed in the results and discussions section.

\subsubsection{Exposures and Personnel Protection}

The subjects identified during the observation phase of the risky procedure were the subject of dosimetric monitoring. The team is made up of a surgeon (Radiologist R) in charge of medical procedures. She may be helped in her tasks by an operating assistant $(\mathrm{O} 2)$, a nurse anesthetist (A2) responsible for managing the patient's pain and a manipulator (M2) responsible for taking care of the patient upon arrival in the department. They also assist the Radiologist so that the examination can take place in the best conditions of comfort and safety. The positioning of the different personnel depends, among other things, on the anatomical region explored, the multiple incidences as well as the type of acquisition (fluoroscopy and radiography). The primary operator (surgeon) was usually placed closer to the patient than other operators during fluoroscopy. In order to protect against exposure to primary and scattered X-ray beams, individual and collective radiation protection measures have been taken. All four operators wore a lead apron and thyroid guard. The manipulator (M) positioned at the control console located behind a lead screen of $2 \mathrm{~mm}$ lead equivalent only enters 
the room when necessary. The available eye protection glasses have been used less because their number is insufficient and their usefulness has often been questioned [3].

\subsection{Radiological Risk Assessment}

The Harshaw 6600 Plus system, consisting of a reader and dosimeters whose performance characteristics and overall uncertainty [4] [5] were evaluated before use, allowed the doses received by the operators to be assessed according to their position in the room. For the dosimetric evaluation, each operator was equipped with one or more dosimeters to assess the effective dose and equivalent doses to the extremities and lens of the eye for the radiological procedure performed.

\subsubsection{Evaluation of the Effective Dose}

For the evaluation of the effective dose, all members of the operating team wore, during each of their operations, two TLD-100 passive dosimeters at the level of the chest, under and above the lead-coated gowns. The quantity measured by this dosimeter was the individual dose equivalent at depth at $10 \mathrm{~mm} \mathrm{Hp} \mathrm{(10),} \mathrm{an}$ estimator of the effective dose to the whole organism.

\subsubsection{Evaluation of Extremity Equivalents}

The dose equivalent $\mathrm{Hp}(0.07)$ at the extremities was evaluated only for the principal radiologist, using extremity dosimeters type TLD X-100 (ref. 24794) fixed on adhesive films positioned on banners labeled and suitable for knees, elbows, ankles, wrists. Only the index fingers were monitored because in practice and in the literature it is the index finger that is the most active and contributes more to carrying out acts. The devices) are worn before each intervention, on the dorsal surfaces of both feet (knees and ankles), on the dorsal surfaces of both hands (wrists) after surgical washing of the hands. At the level of the indexes, the dosimeters were positioned directly on the skin to comply with the usual working conditions [6]. The choice of these locations was decided during the analysis phase by the practitioners who wished to maintain their ease during the procedures.

\subsubsection{Evaluation of the Equivalent Dose to the Lens of the Eye}

The eyes of the radiologist are relatively close to the marking grid. It then appeared interesting to us to evaluate the equivalent dose received at the level of the lens. Two TLD X-100 Temp-Oriented Dosimeters were attached with a film on a headband worn on the radiologist's forehead on the most exposed side of the face and closest to the eye. We will consider that this measured dose will be very close to the value of the dose equivalent to the lens of the eye Hp (3) due to the positioning of the dosimeter and the photonic nature of the radiation [7].

\subsubsection{Estimation of Annual Effective and Equivalent Doses}

The dosimetric evaluations were extrapolated to the annual activity to characterize the operators according to the equation: 
Dose Annual $=$ Cumulative dose $/$ month $* 11$

The potential doses received annually were estimated based on the cumulative doses recorded by the dosimeters for each location The maximum monthly intervention retained was five interventions. By adding up the doses of all the interventions for each location, we obtain the value of the menstrual dose. By projecting this value by a factor of eleven, we obtain the annual dose. Regarding the double dosimetry (two dosimeters were worn, one above and the other below the lead apron), the effective dose was estimated using the expression $\mathrm{E}=\mathrm{Hp}(10) \mathrm{u}$ $+0.05 \mathrm{Hp}(10) \mathrm{o}$ [8] where $\mathrm{u}$ and $\mathrm{o}$, respectively, represent the measurements made below and above the lead apron.

\section{Results and Discussions}

\subsection{Practical Exposure Parameter}

The variations of times, fluoroscopy (green), script (blue) and intervention (yellow) as a function of the number of procedures were presented in Figure 2. The results show, mean fluoroscopy times of $32.37 \mathrm{~min}$ with extremes of 25.14 to $56.32 \mathrm{~min}$; mean writing times of $0.52 \mathrm{~min}$ with extremes of 0.12 to $1 \mathrm{~min}$. The fluoroscopy is used for half or a third of the operating time compared to the graphing which is used less. This shows the importance of using X-rays in interventional radiology. The main factor of exposure highlighted is the total time of use of the fluoroscopy. This time varies considerably from one type of intervention to another, but also for the same type of intervention. This variability is dependent on the radiologist. This can be explained by the skill, slowness and lack of knowledge in terms of radiation protection of the radiologist when raising the probe (catheter) through the femur in the patient. To reduce these exposures, surgeons must be made aware of radiation protection, which will considerably reduce the time of fluoroscopic imaging and the dose received [9]. On the other hand, our results presented in Figure 4 are in agreement with those expressed in

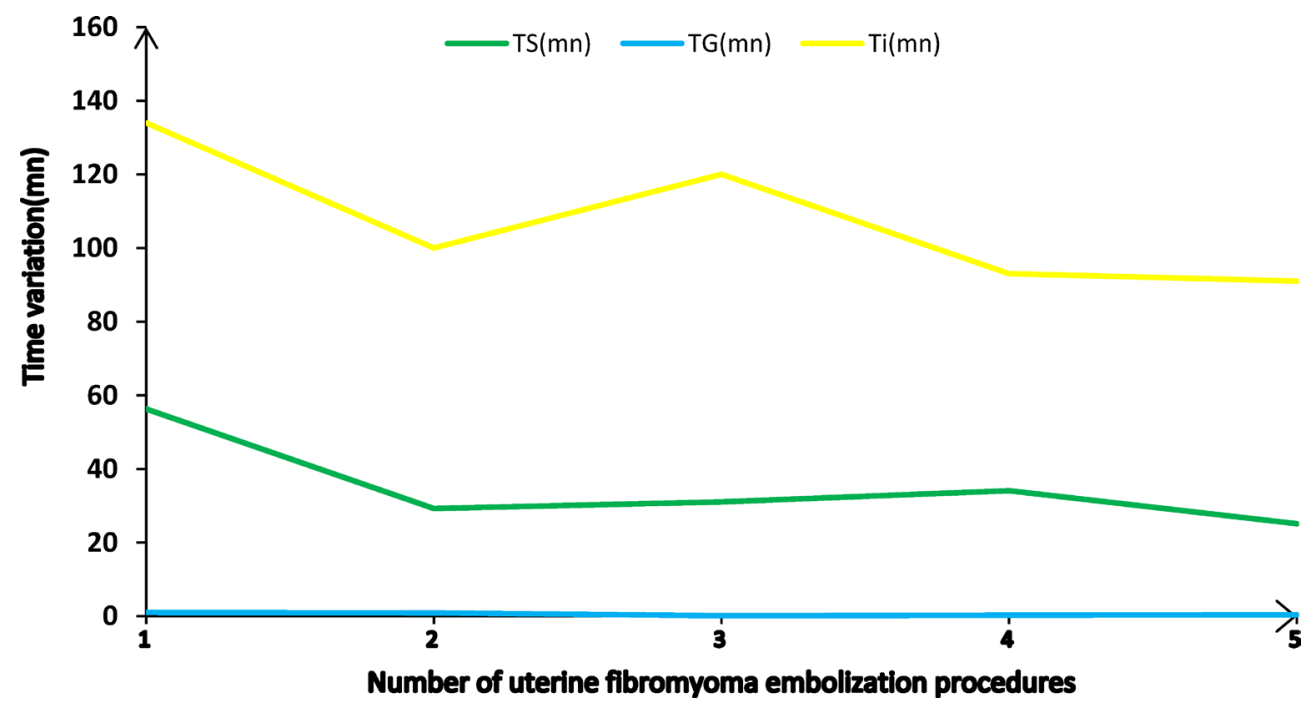

Figure 2. Variability of exposure parameters by number of procedures. 
the literature [3].

\subsection{Effective Dose}

The whole body dose distributions above and below the lead apron of the entire surgical team during the five Uterine Fibromyoma embolization procedures have been shown in Figure 3 In the figure, the white dot represents the mean, the lower (Q1-min) and upper (max-Q3) error bars represent the dispersions; the black dots are the minimum and the maximum connected by the black line which corresponds to the range of values measured at the breast, the red box corresponds to the difference of quartile 3 and quartile 1 . The ranges of variations at the breast of all teams were respectively from $0.38 \mathrm{mSv}$ to $0.14 \mathrm{mSv}$ with an average value of $0.24 \mathrm{mSv}$ above the apron and from $0.01 \mathrm{mSv}$ to $0.08 \mathrm{mSv}$ with an average value of $0.04 \mathrm{mSv}$ below the apron lead. In general, the average value (per procedure) is always less than $0.3 \mathrm{mSv}$, although above the lead apron the range of values can vary considerably from one stakeholder to another due to the inhomogeneity of the field and the positioning of the personnel. The vast majority of doses of people assessed under the lead apron remained below the detection threshold of $100 \mu \mathrm{Sv}$, which confirms the effectiveness of wearing lead aprons as a means of personal protection. The lead apron correctly attenuates the radiation by reducing it to the measured value of the background noise. Moreover, we note that for the average values found in our study below the whole body are of the same order of magnitude as the lowest values published in the literature [7] [10]. The effective dose received by the radiologist most often placed in front of the X-ray tube or to its left, is greater than in other operators located on the other side of the main from the X-ray tube. This can be explained by the positioning of each relative to the $\mathrm{x}$-ray tube.

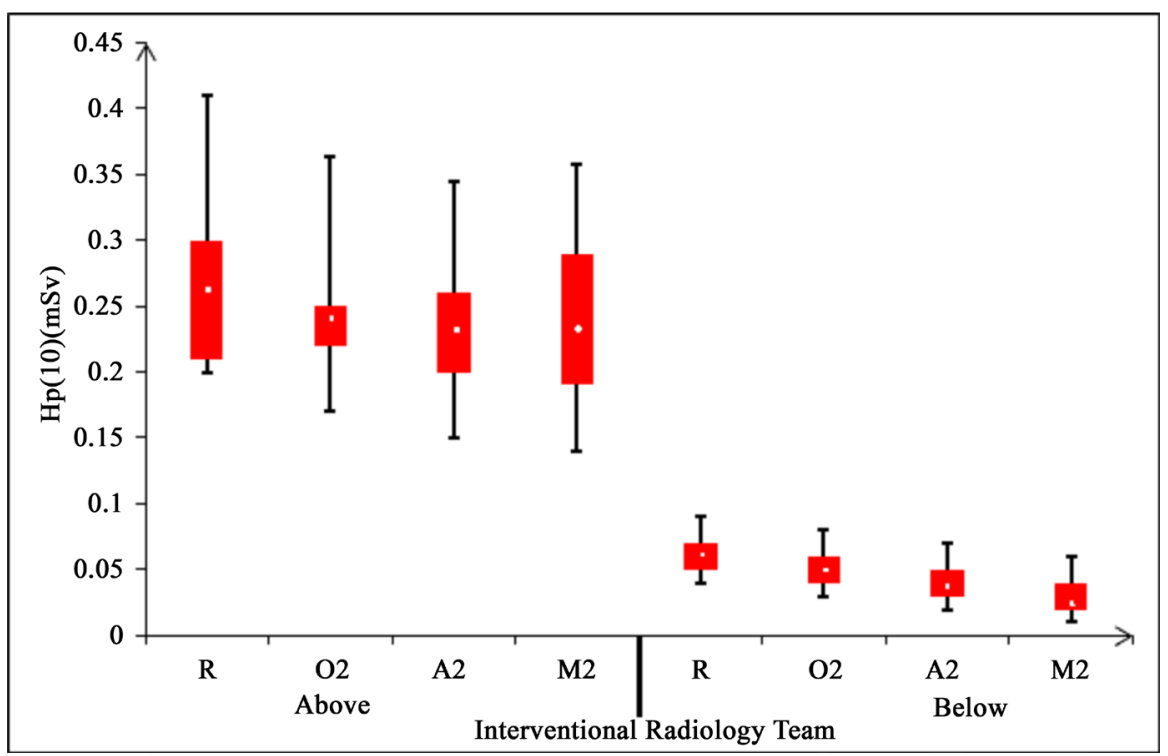

Figure 3. Hp dose variation ranges (10) according to the different members of the interventional radiology team. 


\subsection{Extremity Equivalent Dose Distributions}

The anatomical distributions of the percentage of non-zero doses recorded for the radiologist were presented in Figure 4 and made it possible to identify the most exposed areas. There are $56 \%$ of non-zero doses recorded on the hands, $19 \%$ of non-zero doses recorded on the knees and ankles, $16 \%$ of non-zero doses recorded on the arms (elbows), 9\% of non-zero doses recorded on the lens (eyes) of the operator. These percentages represent a very large proportion of exposure in terms of radiation protection and confirm the choice of body areas that were the subject of dosimetric monitoring during this study

\subsection{Dose Equivalent to the Extremities Placed on the Right and Left Limbs (Arm, Knee, and Ankle)}

Figure 5 shows a concise summary of $\mathrm{Hp}(0.07)(\mathrm{mSv})$ dose values per procedure for, left and right arm (elbow), left and right ankle, left and right knee. In this figure, the white point represents the mean, the lower (Q1-min) and upper (max-Q3) error bars represent the dispersions; the black dots are the minimum and the maximum connected by the black line which corresponds to the range of values measured at the chest. The red box corresponds to the difference of quartile 3 and quartile 1 at each position. The ranges of variation of the left and right lateral limbs were $0.25 \mathrm{mSv}$ to $0.32 \mathrm{mSv}$ with an average of $0.29 \mathrm{mSv}$; from 0.17 to $0.29 \mathrm{mSv}$ with an average of $0.23 \mathrm{mSv}$; from 0.17 to $0.26 \mathrm{mSv}$ with an average of $0.21 \mathrm{mSv}$; from 0.12 to $0.21 \mathrm{mSv}$ with an average value of $0.18 \mathrm{mSv}$; from 0.08 $\mathrm{mSv}$ to $0.15 \mathrm{mSv}$ with an average of $0.11 \mathrm{mSv}$, from $0.03 \mathrm{mSv}$ to $0.11 \mathrm{mSv}$ with an average of $0.07 \mathrm{mSv}$ respectively for the left and right elbow, left and right

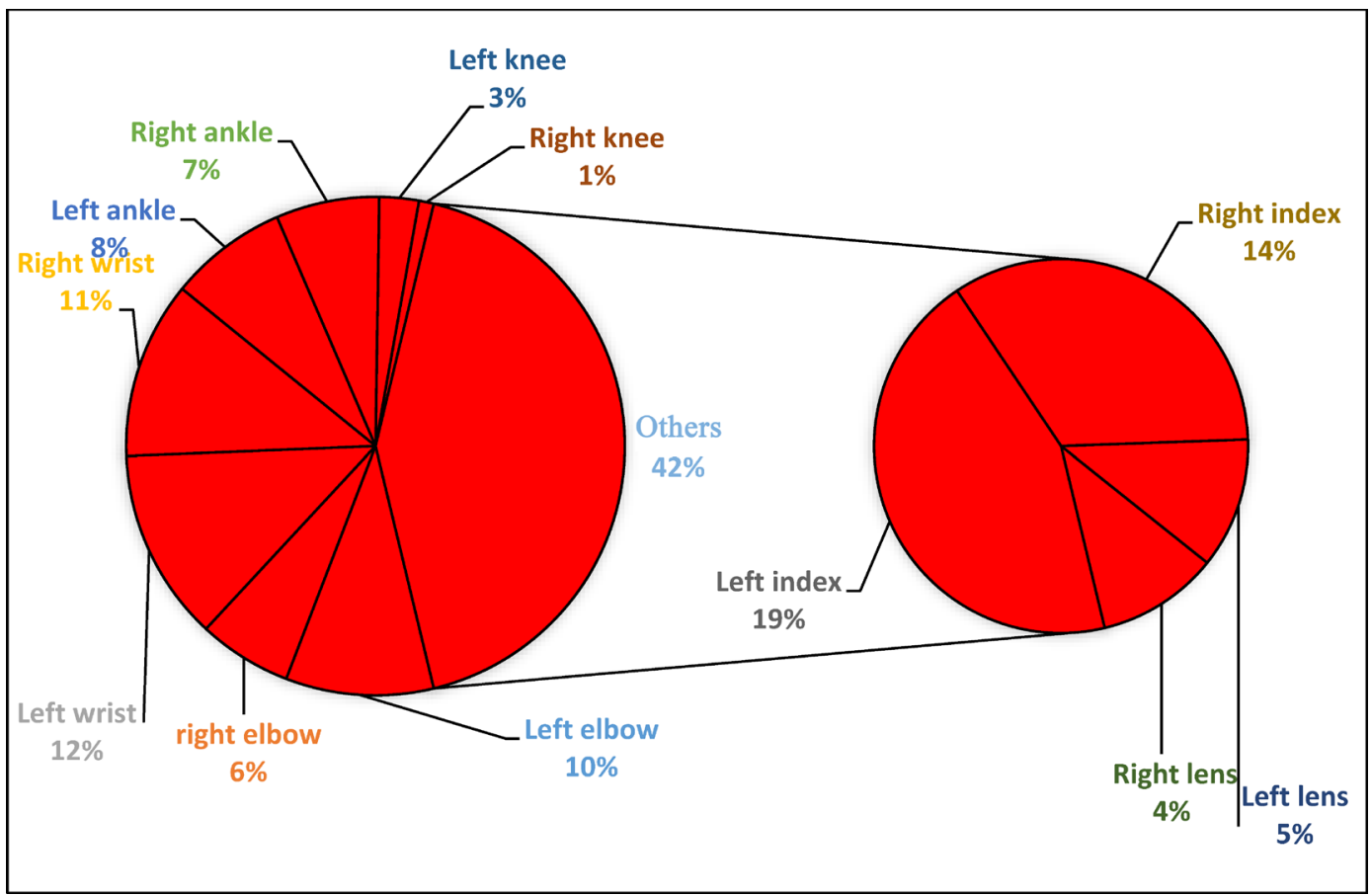

Figure 4. Anatomical distributions of the percentage of non-zero doses recorded for the radiologist. 


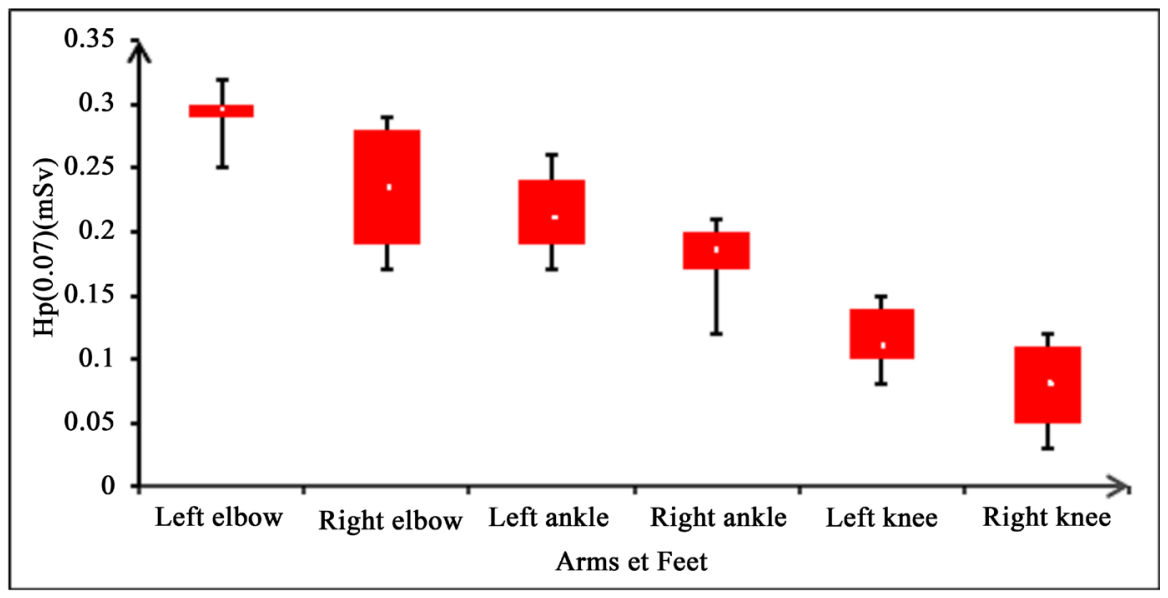

Figure 5. Summary of $\mathrm{Hp}(0.07)(\mathrm{mSv})$ dose values per procedure for arms (elbows) and feet (knees, ankles).

ankle, left knee and right. It can be observed that for all the procedures that the left lateral limbs were more exposed (maximum of $0.32 \mathrm{mSv}$ for the left arm (elbow)) because they were closer to the radiation plane. The left side of the radiologist corresponds to the side dominant because the dose values are higher than the right side (non-dominant side). In contrast, the right limbs never exceeded $0.29 \mathrm{mSv}$. This difference can then be explained by the position of the radiologist in relation to the operating table. For all procedures, the left arm (elbow) received a higher range of dose values than the ankle and knee, in that order. The same was verified for the right limbs in the same order as the left limbs. The mean dominant ankle dose was low and the maximum did not exceed $0.22 \mathrm{mSv}$ in all procedures studied. The dose range at the knee appears to have been even lower, most likely because the dosimeter placed at the knee was often in the shadow of the lead apron.

\subsection{Equivalent Dose to the Extremities of the Hands (Wrists and Index Finger)}

Exposure of hands and fingers can cause acute or chronic radiodermatitis. The chronic form is most often the result of multiple medical exposures in high-risk specialties such as radiology, cardiology and vascular, digestive, urinary and orthopedic surgery [11]. Figure 6 presents a concise summary of Hp (0.07) (mSv) dose values per procedure is for the wrist of the left hand and right hand, the left and right index finger. In the figure, the white point represents the mean, the lower (Q1 min) and upper (max-Q3) error bars represent the dispersions; the black dots are the minimum and the maximum connected by the black line which corresponds to the range of values measured at the chest. The red box corresponds to the difference of quartile 3 and quartile 1 at each position. The ranges of variations of the wrist, the left hand, the right hand as well as the index, left and right were respectively from $0.39 \mathrm{mSv}$ to $0.65 \mathrm{mSv}$ with an average of $0.53 \mathrm{mSv}$; from $0,31 \mathrm{mSv}$ to $0.58 \mathrm{mSv}$ with an average of $0.41 \mathrm{mSv}$; from 0.59 


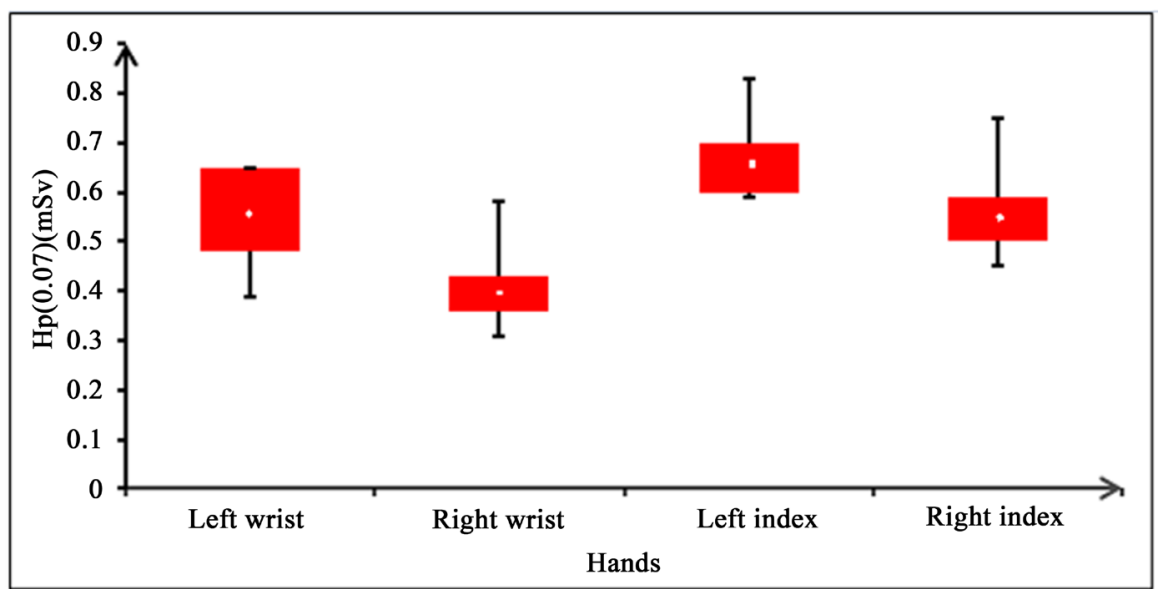

Figure 6. Summary of $\mathrm{Hp}(0.07)(\mathrm{mSv})$ dose values by hand procedure (wrists and index finger).

$\mathrm{mSv}$ to $0.83 \mathrm{mSv}$ with an average of $0.67 \mathrm{mSv}$; from $0.45 \mathrm{mSv}$ to $0.75 \mathrm{mSv}$ with an average of $0.56 \mathrm{mSv}$. In this work, the highest dose was recorded in the left hand. It is the non-dominant hand because the radiologist is right-handed. Similarly, measurements at the wrist on both the non-dominant hand $(0.65$ $\mathrm{mSv})$ and the dominant hand $(0.58 \mathrm{mSv})$ show very low values compared to the doses of the index finger $(0.75 \mathrm{mSv}$ and $0.83 \mathrm{mSv})$. Therefore, the wrist position does not describe the dose received by the hand well and should not be used as a routine monitoring position. The primary operator's exposure to radiation should be carefully monitored at the fingertips. Our results compared to those published in the literature [12] [13] [14] can be explained by the type of intervention, the number of procedures and the method used to assess the dose. To prevent the hand from being exposed in the primary beam and increase the distance of the hand to the irradiation plane, thus reducing the dose received from the non dominant hand we recommend needle holders instead of the use of lead gloves which are questionable [15].

\subsection{Dose Equivalent to the Lens of the Eye}

The lens of the eye is one of the most radiosensitive tissues in the body, and exposure of the lens to ionizing radiation can cause radio-induced cataracts and cloudiness of the lens [16]. The dose distributions shown in Figure 7 indicate $4 \%$ and 5\%, respectively, of non-zero doses recorded to the left and right lenses of the main operator of our study during the procedures. These percentages are significantly low compared to the other bodies in our study. However, they are not negligible in terms of radiation protection. A concise summary of the procedural Hp (0.07) dose values obtained at the left (left eye) and right (right eye) temples is shown in Figure 7 based on statistical parameters such as, mean, dispersion and the extent.The ranges of variations were from $0.11 \mathrm{mSv}$ to $0.24 \mathrm{mSv}$ with an average of $0.17 \mathrm{mSv}$; from $0.10 \mathrm{mSv}$ to $0.15 \mathrm{mSv}$ with an average of 0.13 $\mathrm{mSv}$ respectively for the left temple (left eye) and right (right eye). The maximum 


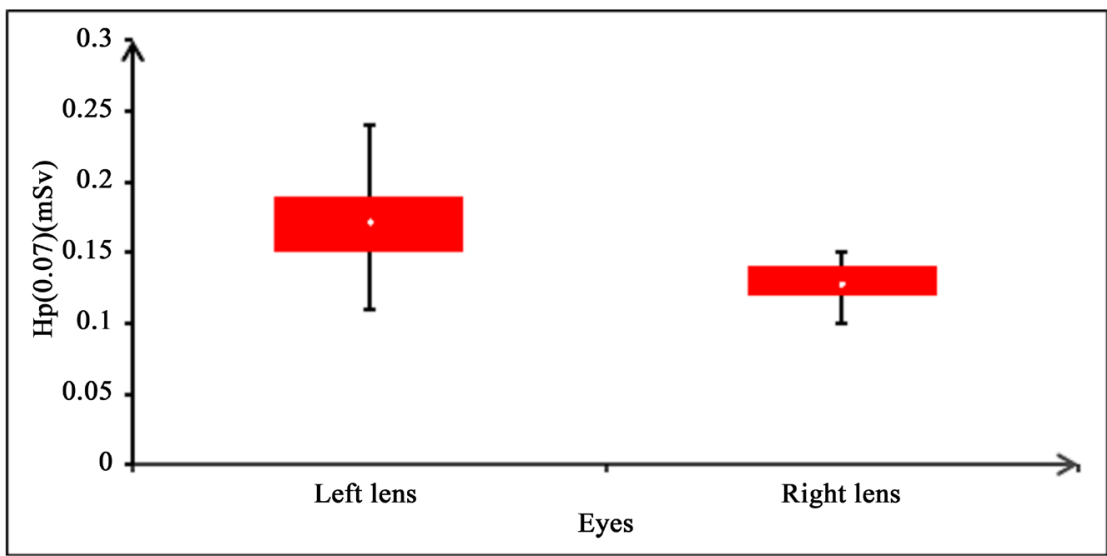

Figure 7. Summary of $\mathrm{Hp}(0.07)(\mathrm{mSv})$ dose values by lens of the eye procedure (left and right temple).

dose recorded during embolization procedures is $0.24 \mathrm{mSv}$ at the left temple compared to $0.15 \mathrm{mSv}$ at the radiologist's right temple. In our study and what is found in the literature, the X-ray tubes are on the operator's left. Therefore, this important difference observed between the dose measured at the tube side eye (left eye) compared to the other eye According to Chong, et al. (2000) [17] lies in the orientation of the head of the operator according to the layout of the display screens, hence the importance of correct positioning of the interventionist's head [18]. As noted by IRSN in its report [19] on exposure of the lens in interventional radiology, the comparison between the various data published in the literature is difficult. This is because of the differences in the dose measurement conditions ( $\mathrm{Hp}$ (0.07), with and without protection, type of procedures, etc.). In the case of our study, the existence of ceiling protection and the use of radiation protection glasses also help to keep exposure to a lower level.

\subsection{Annual Dose Estimates}

For the five (5) procedures considered the sum of the dose values for the whole body at the chest, above and below the lead apron gave respective yields of 1.35 $\mathrm{mSv}$ and $0.3 \mathrm{mSv}$ for the Radiologist (R). Based on the double dosimetry algorithm, the effective dose to the chest was $0.36 \mathrm{mSv}$ for the Radiologist (R). A projection over one year, assuming a maximum number of procedures performed by the single radiologist in one year of 55 Uterine Fibromyoma Embolization gave $4.04 \mathrm{mSv}$ as an annual effective dose. The annual dose was compared to the annual exposure limits naturally recommended at the international level by ICRP 60 [20], which is $20 \mathrm{mSv}$ per for a category A worker and $6 \mathrm{msv}$ for a category B worker. Similar reasoning allowed to have respectively the effective annual doses of $3.42 \mathrm{mSv}, 2.84 \mathrm{mSv} ; 2.28 \mathrm{mSv}$, O operators; A, M. These values compared to the annual exposure limit in Figure 8 are not of concern. Based on the same reasoning of cumulative doses of all the procedures in equation (I), the equivalent doses to the arms (left and right elbow), wrists (left and right), Index (left and right), on the knees (left and right), ankles (left and right), lens (left and 


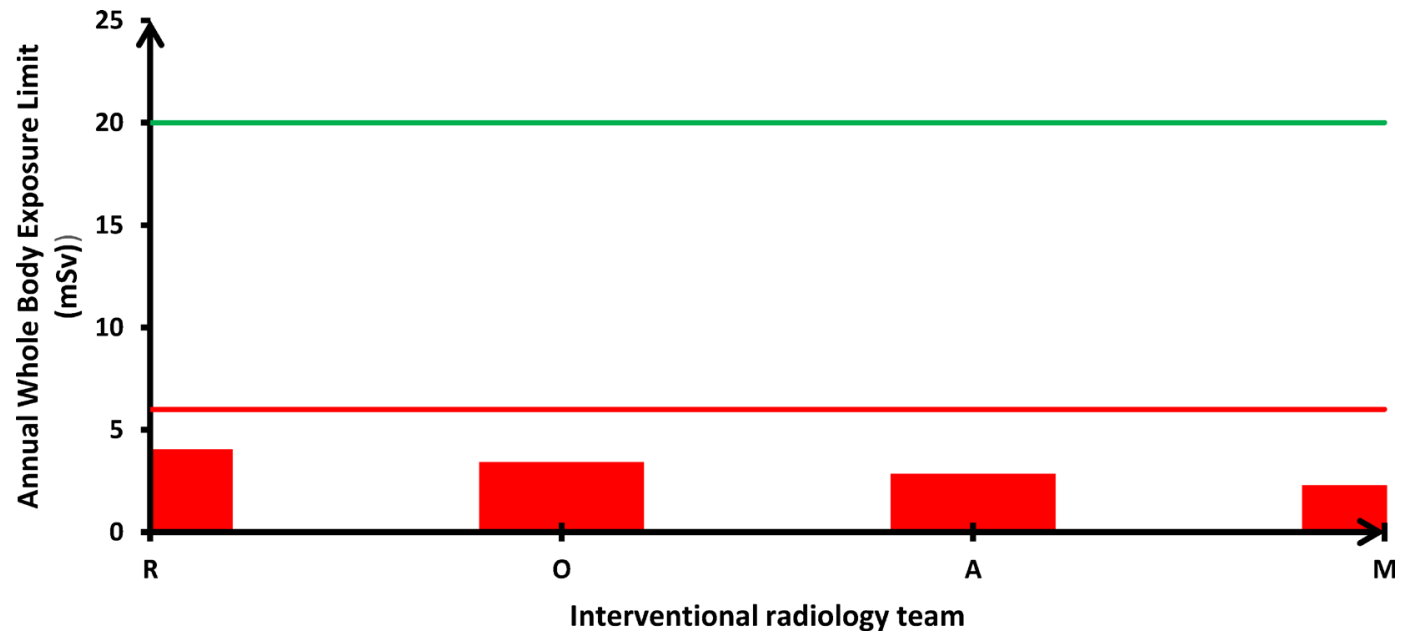

Figure 8. Annual effective dose Hp (10) comparisons to ICRP 60 (20 mSv and $6 \mathrm{mSv}$ ).

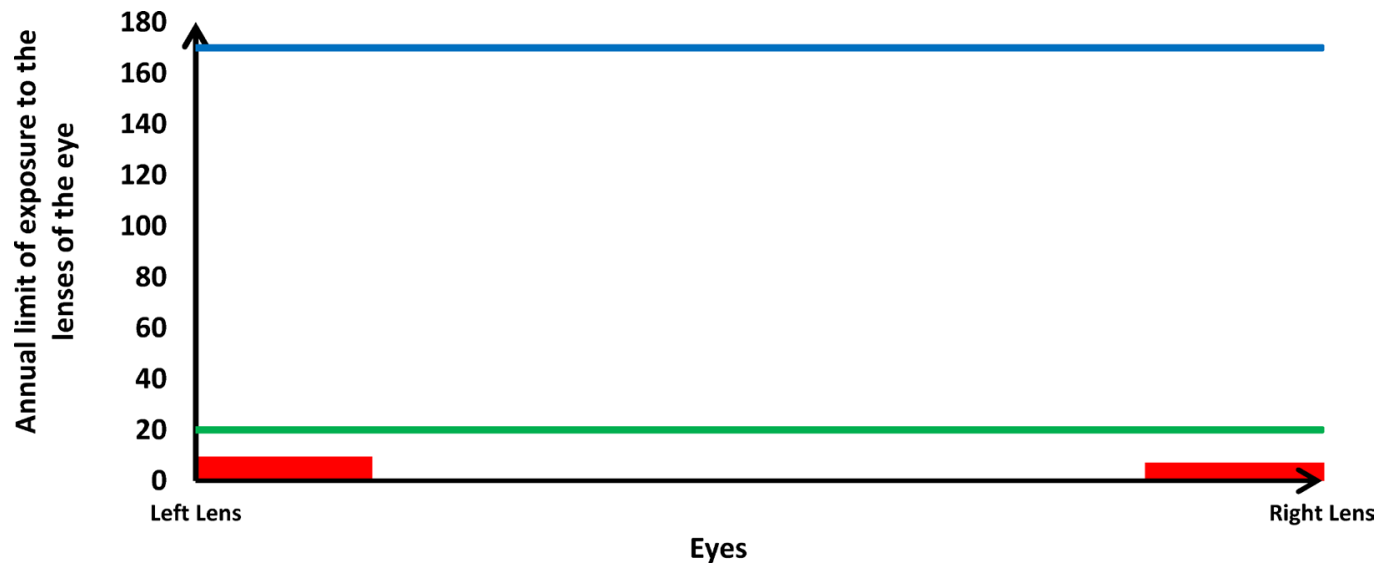

Figure 9. Annual dose Hp (0.07) comparisons ( $\mathrm{mSv}$ to crystalline lens versus ICRP 60 (150 mSv) and new regulations in effect July 1, 2023 (20 mSv).

right eye) gave yields of $1.46 \mathrm{mSv}$ and $1.17 \mathrm{mSv}$, respectively; $2.68 \mathrm{mSv}$ and 2.08 $\mathrm{mSv}$; $3.37 \mathrm{mSv}$ and $2.87 \mathrm{mSv}$; $0.59 \mathrm{mSv}$ and $0.41 \mathrm{mSv}$; $1.06 \mathrm{mSv}$ and $0.86 \mathrm{mSv}$; of $0.86 \mathrm{mSv}$ and $0.65 \mathrm{mSv}$ The same projection as above gives annual equivalent doses to the same organ of $16.06 \mathrm{mSv}$ and $12.87 \mathrm{mSv} ; 29.48 \mathrm{mSv}$ and $22.88 \mathrm{mSv}$; of $37.07 \mathrm{mSv}$ and $30.91 \mathrm{mSv} ; 6.49 \mathrm{mSv}$ and $4.51 \mathrm{mSv} ; 11.66$ and $9.76 \mathrm{mSv} ; 9.46$ $\mathrm{mSv}$ and $7.15 \mathrm{mSv}$. Consequently, these annual values remained below the annual dose limit at the extremities and at the lens of $500 \mathrm{mSv}$ and $150 \mathrm{mSv}$ [21] of Figure 9 and Figure 10. Concerning the equivalent doses to the lens, the transposition into French law of the Directive Euratom 2013/59 [21], will lower the limit of exposure to the lens of the eye to $15 \mathrm{mSv}$ for the public and $20 \mathrm{mSv}$ for exposed personnel (categorized) [22]. From the above, these limit values will be applied by international regulations July 1,2023 . The annual equivalent dose to the dominant lens of our study of $9.46 \mathrm{mSv}$ should in fact result in little change in personnel classification since 88 procedures per year would be necessary to exceed the limit of $15 \mathrm{mSv}$. However, for the team of our study, the number of 117 annual interventions should not be reached under penalty of exceeding the 


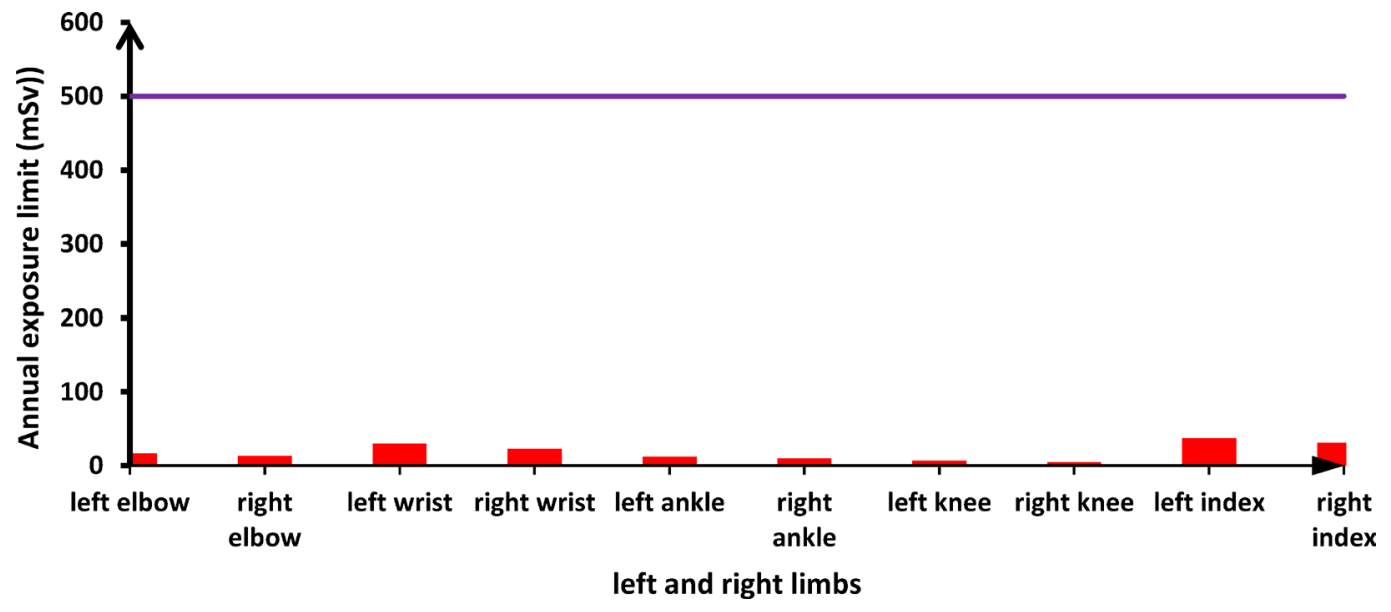

Figure 10. Annual Hp dose (0.07) comparisons (extremity mSv vs ICRP 60 (500 mSv)).

limit of $20 \mathrm{mSv}$ in the lens. Taking all these considerations into account, we can conclude that the effective and equivalent annual doses received by the radiologist and her team are much lower than the annual values. The radiologist and the other members of the team are poorly exposed to ionizing radiation and the staff run no risk of a deterministic effect on the various organs that have been monitored. However, there is a risk of a stochastic effect.

\section{Conclusion}

In definitive, this study provided the interventional radiology team with the very first assessment of their exposure to ionizing $\mathrm{x}$ radiation in the course of their job. The risk analysis and assessment showed great variability in the doses received, to the whole body, extremities and crystalline lenses of the different members of the operating team. Many influencing factors such as the abundant use of X-rays, the nature of the acts, the non-quality control of the installations, the imperfect use of collective protective equipment (EPC) and personal protective equipment (PPE) and ignorance of radiation protection rules and principles are at the origin of this variability. In addition, extrapolating the doses measured over the year by taking into account all the influencing factors. In the case, our study reveals an acceptable risk of exposure, but not negligible over time for all stakeholders. From these data, a radiation protection program for better routine monitoring of the dominant left arm (elbow), left (non-dominant) hand and eyes of the radiologist could be developed, as could the development of a culture radiation protection within the team could also reduce doses.

\section{Conflicts of Interest}

The authors declare no conflicts of interest regarding the publication of this paper.

\section{References}

[1] Jacob, S., Boveda, S., Bar, O., et al. (2012) Interventional Cardiologists and Risk of 
Radiation-Induced Cataract: Results of a French Multi-Center Observational Study.

[2] Innova (2015) Guide d'utilisation. Innova TM IGS 520, Innova TM IGS 530, InnovaTM IGS 540 Direction 5499294-1-1FR, Revision 2.

[3] Pégorié, A., et al. (2017) Chirurgie endovasculaire: Évaluation de l'exposition radiologique et proposition d'axes d'amélioration. Archives des Maladies Professionnelles et de I Environnement, 79, 34-45. https://doi.org/10.1016/j.admp.2017.09.004

[4] Kouakou, O., Monnehan, G.A. and Huberson, G.B.D.L. (2019) Impact of Harshaw 6600 plus Reader's Electronic Parameter Stability on Precision Dose Measurements of Workers Exposed to Ionizing Radiation in Côte d'Ivoire. International Journal of Innovation and Applied Studies, 25, 1181-1188.

[5] Kouakou, O., Monnehan, G.A. and Huberson, G.B.D.L. (2019) Evaluation of Dosimetric Performance and Global Uncertainty of the Harshaw 6600 plus System Used to Staff Monitoring in Côte d'Ivoire. World Journal of Nuclear Science and Technology, 9, 159-173. https://www.scirp.org/journal/wjnst https://doi.org/10.4236/wjnst.2019.94012

[6] Amoussou-Guenou, K.M., Soglo, R.T., Sosu, E., Darko, E.O. and Amuasi, J.H. (2013) Évaluation de l'exposition des travailleurs du service de radioimmuno-analyse du Bénin aux rayonnements ionisnts de l'iode 125 .

[7] Abou Anoma, G., et al. (2012) Cardiologie interventionnelle: Evaluation de l'exposition aux rayonnements ionisants et zonage radiologique. Archives des Maladies Professionnelles et de P Environnement, 73, 849-859. https://doi.org/10.1016/j.admp.2012.09.004

[8] (2015) Decreto-Lei 184, Diário da República. Imprensa Nacional da Casa da Moeda. 6615-6631.

[9] Müller, M.C., Welle, K., Strauss, A., Naehle, P.C., Pennekamp, P.H., Weber, O., et al. (2014) Real-Time Dosimetry Reduces Radiation Exposure of Orthopaedic Surgeons. Orthopaedics \& Traumatology: Surgery \& Research, 100, 947-951. https://doi.org/10.1016/j.otsr.2014.09.016

[10] Alves, J.G., Sarmento, S., et al. (2019) Dose to the Interventional Radiologist in CTF-Guided Procedures. Radiation and Environmental Biophysics, 58, 373-384. https://doi.org/10.1007/s00411-019-00792-3

[11] Chambers, J.A. and Long, J.N. (2008) Radiation Injury and the Hand Surgeon. Journal of Hand Surgery (American Volume), 33, 601-611. https://doi.org/10.1016/j.jhsa.2008.01.035

[12] Müller, L.P., Suffner, J., Wenda, K., Mohr, W. and Rommens, P.M. (1998) Radiation Exposure to the Hands and the Thyroid of the Surgeon during Intramedullary Nailing. Injury, 29, 461-468. https://doi.org/10.1016/S0020-1383(98)00088-6

[13] Fuchs, M., Modler, H., Schmid, A., Dumont, C. and Stürmer, K.M. (1999) Measuring Intraoperative Radiation Exposure of the Trauma Surgeon. Measuring Eye, Thyroid Gland and Hand with Highly Sensitive Thermoluminescent Detectors. Unfallchirurg, 102, 371-376. https://doi.org/10.1007/s001130050420

[14] Singer, G. (2005) Radiation Exposure to the Hands from Mini C-Arm Fluoroscopy. Journal of Hand Surgery (American Volume), 30, 795-797. https://doi.org/10.1016/j.jhsa.2005.01.007

[15] Guersen, J., Donadille, L., Rehel, J.L., Charvais, A., Zaknoune, R., Cassagnes, L., et al. (2011) Intérêt des gants radio-atténuateurs en radiologie interventionnelle: Une évaluation expérimentale. Radioprotection, 46, 387-397. https://doi.org/10.1051/radiopro/2011113

[16] Vano, E., et al. (2010) Radiation Cataract Risk in Interventional Cardiology Per- 
sonnel. Radiation Research, 174, 490-495. https://doi.org/10.1667/RR2207.1

[17] Chong, N., Yin, W., Chan, P., Cheng, M., Ko, H., Jeng, S. and Lee, J. (2000) Evaluation of Absorbed Radiation Dose to Working Staff during Cardiac Catheterization Procedures. Chinese Medical Journal, 63, 816-821.

[18] Cousin, A.J., Lawdahl, R.B., Chakraborty, D.P. and Koehler, R.E. (1987) The Case for Radioprotective Eyewear/Facewear: Practical Implications and Suggestions. Investigative Radiology, 22, 688-692.

https://doi.org/10.1097/00004424-198708000-00012

[19] IRSN, Réalisation des études dosimétriques de poste de travail présentant un risque d'exposition aux rayonnements ionisants (Version 4). Rapport PRP-HOM/DIR No. 2015-00009. Guide pratique pour la réalisation des études dosimétriques de poste de travail (Version 4).

[20] ICRP (1991) Recommandations of the International Commission on Radiological Protection. ICRP Publication 60, Pergamon Press, Oxford.

[21] Directive 2013/59/Euratom du Conseil du 5 décembre 2013 fixant les normes de base relatives à la protection sanitaire contre les dangers résultant de l'exposition aux rayonnements ionisants et abrogeant les directives 89/618/Euratom 90/641/ Euratom, 96/29/Euratom, 97/43/Euratom et 2003/122/Euratom. http://eurlex.europa.eu/legal-content/FR/TXT/HTML/?uri=CELEX:32013L0059

[22] Rapport IRSN PRP-HOM 2013-00010 "Recommandations sur les bonnes pratiques en matière de radioprotection des travailleurs dans la perspective de l'abaissement de la limite règlementaire de dose équivalente pour le cristallin”. 